\title{
The outcome of stapedotomy in adult patients with clinical otosclerosis in Erbil
}

\begin{tabular}{|c|c|c|}
\hline Hanna Khanano Kasho* & Abdulkhaliq Emin* & Lana Abdul Razaq Dabbagh* \\
\hline & Abstract & \\
\hline
\end{tabular}

Background and objective: Otosclerosis is a primary disease of the temporal bone that leads to stapes fixation. Hearing loss and tinnitus are the main symptoms. Treatment includes surgery, medical treatment, and sound amplification therapy alone or in combination. This study aimed to evaluate the functional outcomes of patients with clinical diagnosis of otosclerosis undergoing primary stapes surgery in Erbil city.

Methods: A retrospective descriptive study. A total of 32 patients with clinical otosclerosis underwent unilateral stapedotomy in the specialized center between September 2011 and September 2013. These included 20 females and 12 males, aged 21 to 48 years, their mean age $( \pm S D)$ was $31.9( \pm 10.91)$ years.

Results: The average preoperative and postoperative air conduction threshold was 51.13 and $23.91 \mathrm{~dB}$, respectively. The mean preoperative and postoperative bone conduction threshold was 21.53 and $16.21 \mathrm{~dB}$, respectively. The average preoperative and postoperative air-bone gap was 29.03 and $8.51 \mathrm{~dB}$, respectively. All 32 ears (100\%) had a residual air-bone gap $<10 \mathrm{~dB}$.

Conclusion: Stapes surgery showed significant functional hearing outcomes in this study. The very significant reduction in the air-bone gap is a good indicator of the success of the surgery.

Keywords: Hearing loss; Otosclerosis; Stapes surgery.

\section{Introduction}

Otosclerosis is defined as a continuous process of bone remodeling in which there is an alteration in bone metabolism of the ottic capsule in the form of bone resorption and re-deposition. Unlike other similar bone diseases, it does not occur outside of the temporal bone. The formation of centers of newly constructed bone, usually occurs in the area of the oval window and annular ligament, leading to stapes fixation. ${ }^{1}$ Otosclerosis was first described by Vasalva in 1735 as ankylosis of the stapes to the margins of the oval window. ${ }^{2}$ It is well known that otosclerosis has clinical and histological forms. The clinical form of otosclerosis refers to the presence of symptoms like hearing loss and tinnitus. While the histological form the disease is present without symptoms. Histologically demonstrated that otosclerosis is about ten times more common than clinical otosclerosis. ${ }^{3}$ The overall incidence of otosclerosis reveals the variability in distribution according to race, gender, geographic location, familial incidence, pregnancy, and age. The disease occurs more frequently in the Caucasian race (white race) than in other races. ${ }^{4,5}$ It is less common in Asians and rare in Africans. There has been an increasing incidence of otosclerosis in Japan. ${ }^{6}$ Otosclerosis process usually affects young adults and people between 15 and 45 years of age. ${ }^{7}$ The incidence of otosclerosis described in the literature ranges between 0.3 and $2 \%$. Souza et al. $^{8}$ indicated that clinical otosclerosis is present in $0.5 \%$ to $1.0 \%$ of the population. In 2001, Declau et al. $^{9}$ stated that clinical otosclerosis has a prevalence of $0.3 \%$ to $0.4 \%$ among the white ethnic population. A recent Jordanian

* Department of Otolaryngology, College of Medicine, Hawler Medical University, Erbil, I raq. 
study $^{10}$ reported that the incidence of clinical otosclerosis in the general population is about $2 \%$. Majority of patients with otosclerosis has the disease in both ears. Bilateral symptoms have been reported in $70 \%$ to $85 \%$ of cases. ${ }^{8}$ Many studies have indicated that the clinical form of otosclerosis is twice more common in women than in men. ${ }^{11}$ However, when it comes to the histological form of the disease, the ratio between women and men is $1: 1{ }^{4}$ Current research suggests that heredity, genetic malformations, viral infection, trauma, endocrine disorders, and autoimmune diseases play a role in the etiology of otosclerosis. However, none of the hypotheses is accepted as a unique etiopathogenetic theory. ${ }^{12}$ Most authors agree that this disease is transmitted by autosomal dominant inheritance with varying degrees of penetration of the gene responsible for the development of the disease. ${ }^{13,14}$ Recent studies indicate the existence of nine different chromosomes containing genes responsible for the development of otosclerosis ${ }^{15}$. Furthermore, genetic investigations have identified seven loci (OTSC15, OTSC7, OTSC8), although none of the corresponding genes have been found. ${ }^{16,17}$ It is well-known that pregnancy may trigger the onset of otosclerosis or worsen it. Measles Virus infection is another risk factor implicated in the development of the disease. ${ }^{10}$ The involvement of stapes footplate in patients with otosclerosis causes conductive or mixed hearing loss. Depending on the extent of the process, conductive hearing loss can range from 30 $\mathrm{dB}$ to $50 \mathrm{~dB} .^{18}$ However, sensorineural hearing loss eventually occurs, and its cause has not yet been determined. One of the theories behind the sensorineural hearing loss in otosclerosis is the invasion of the spiral ligament by the disease. ${ }^{19}$ In 1919, Wittmaack suggested that sensorineural hearing loss occurs as a consequence of toxic or inflammatory material deposited within the cochlea. ${ }^{8}$ The definitive diagnosis of otosclerosis is always made by surgical exploration, which confirms the immobility of the stapes and then it is verified histopathologically. Clinical symptoms of otosclerosis include progressive hearing loss and tinnitus. In rare cases, dizziness may occur as well. Historically otosclerosis has been treated both medically and surgically. Of the factors that may inhibit the disease process, fluorides, cytokine inhibitors, and bisphosphonates, however, the medical intervention has not yet been shown to prevent or slow the disease. ${ }^{20}$ Amplification with hearing aids or assistive devices has been indicated. Surgical correction of the conductive hearing loss is highly effective. One of the most important developments in the surgical treatment of conductive hearing loss caused by otosclerosis was the first stapedectomy, performed by John J. Shea, Jr. in May 1956. ${ }^{21}$ Since the surgery by Dr. John J. Shea, numerous techniques have been introduced in an effort to achieve optimal improvement in the hearing loss. Stapedotomy was later established as the gold standard procedure because the limited opening of the vestibule was found to significantly reduce the risk of inner ear damage. It was first performed by Professor Henri Andre Martin. ${ }^{10}$ The main aim of stapes surgery today remains elimination of the $A B G$ or a significant reduction, to within $10 \mathrm{~dB}$. Among large series of stapedotomies, reported air-bone gap (ABG) closure (closed to $<10 \mathrm{~dB}$ ) varied from $94 \%$ $(n=2368)$ to $75 \% \quad(n=861) .{ }^{22,23}$ Patient characteristics, surgical experience, and intraoperative findings may be considered potential prognostic factors affecting postoperative audiometric results. ${ }^{9}$ This study aimed to evaluate the effectiveness of stapedotomy in improving hearing in patients with conductive hearing loss due to otosclerosis.

\section{Methods}

\section{Patients}

A prospective quasi-experimental study of functional hearing results was performed 
before and after surgical treatment of otosclerosis using stapedotomy method at a specialized center in Erbil city, Kurdistan region. The study included patients who were surgically treated from September 2011 through September 2013. All patients were surgically treated by the same surgeon, using the same operative technique (stapedotomy). During that period, 32 patients underwent surgical treatment (20 females and 12 males) aged 21 to 48 years, their mean age $( \pm S D)$ was $31.9( \pm 10.91)$ years.

\section{Surgical procedure}

The operation was performed with an endaural procedure under general anesthesia. The tympanomeatal flap was elevated, and the bone from the posterior scutum was removed with a curette or drill to expose the oval window and the stapes. The mobility of the stapes was checked by mobilizing the malleus handle by a needle. After separating the incudostapedial joint with a joint knife and cutting the stapedial tendon with scissors, the posterior crus of the stapes was divided with a scissor. The anterior crus of stapes was subsequently down-fractured with a microhook and removed. The prosthesis was sized by measuring the distance from the footplate to the long process of the incus. A fenestra of $0.6 \mathrm{~mm}$ in diameter was made at the junction of the posterior one-third and anterior two-thirds of the footplate by a micro-perforator (microdrill). Telfon piston prosthesis was used in all cases. The prosthesis was positioned after the adjustment of its length.

\section{Audiometric assessment}

The diagnostic algorithm included the following analysis procedures: anamnesis, clinical examination, tonal audiometry, tympanometry, stapedial reflex testing. All functional diagnostic procedures were conducted at the specialized Audiology center_applying the tonal Audiometer Interacoustics -AA-222 Audiotraveller and tympanometry. The hearing was measured in a soundproof booth with patients wearing calibrated headphones (TDH39 for conventional-frequency audiometry). First, pure tones at $0.25,0.5,1,2,3,4,6$, and $8 \mathrm{kHz}$ were presented to one ear at a time and thresholds for bone-conducted sound measured by placing a calibrated vibrator on the mastoid process while presenting tones at $0.5,1,2$, and $4 \mathrm{kHz}$. The hearing threshold was identified using the modified Hughson-Westlake method as recommended by the International Standards Organization. These measures were performed before surgery and 6-8 weeks after that. Tonal audiometry results obtained before and after surgery were compared. Bone conduction, air conduction and air-bone (AB gap) threshold at $500 \mathrm{~Hz}, 1000 \mathrm{~Hz}, 2000$ $\mathrm{Hz}$, and $4000 \mathrm{~Hz}$ were compared. Subsequently, we compared the average hearing threshold at hearing frequencies (PTA-pure tone average), bone conduction, air conduction and air-bone threshold before and after surgery. PTA was done for all four voice frequencies by adding the values expressed in $\mathrm{dB}$ at the aforementioned frequencies. The values were then divided by four to obtain the value that can be used in further calculations as the relevant one.

\section{Statistical analysis}

Data were analyzed using the statistical package for the social sciences (version 19). The paired sample t-test was used to compare means, before and after the procedure. A $P$ value of $\leq 0.05$ was considered as statistically significant.

\section{Results}

A total of 32 patients (12 male and 20 female) between 21 - 48 years with a mean $( \pm$ SD) age of $31.9( \pm 10.91)$ years underwent the operation. All patients had bilateral disease, but operations were performed only in one ear (the worse ear). The mean $( \pm$ SD) follow-up period was $28.14( \pm 10)$ weeks and patients with less than three weeks follow-up were excluded from the study. 
The outcome of stapedotomy in adult patients .......

Zanco J. Med. Sci., Vol. 23, No. (1), April, 2019 https:/ / doi.org/ 10.15218/ zjms.2019.001

Hearing results $500,1000,2000$ and $4000 \mathrm{~Hz}$ frequencies.

The air conduction thresholds, bone The preoperative and postoperative conduction thresholds and air-bone gap hearing statuses of patients are (AB-gap) of all patients were evaluated in summarized in Table 1.

Table 1: Preoperative and postoperative audiometric results among 32 patients.

Pure Tone, Mean (SD), dB

\begin{tabular}{lcccr} 
Variable & Before surgery & After surgery & PTA improvement & $P$ value \\
\hline & \multicolumn{3}{c}{ Bone Conduction } \\
$0.5 \mathrm{kHz}$ & $18.75(5.82)$ & $15.31(4.91)$ & 3.44 & 0.019 \\
$1 \mathrm{kHz}$ & $22.97(8.51)$ & $15.94(6.02)$ & 7.03 & $<0.001$ \\
$2 \mathrm{kHz}$ & $26.72(6.30)$ & $17.19(5.67)$ & 8.93 & $<0.001$ \\
$4 \mathrm{kHz}$ & $17.66(4.92)$ & $16.41(6.12)$ & 1.25 & 0.402
\end{tabular}

\section{Air Conduction}

$\begin{array}{lllll}0.5 \mathrm{kHz} & 55.78(5.70) & 23.59(5.71) & 32.19 & <0.001 \\ 1 \mathrm{kHz} & 57.50(7.62) & 22.03(7.06) & 33.91 & <0.001 \\ 2 \mathrm{kHz} & 47.97(8.79) & 21.72(7.47) & 26.25 & <0.001 \\ 4 \mathrm{kHz} & 43.28(7.89) & 28.28(11.40) & 15 & <0.001\end{array}$

Air-Bone Gap

$\begin{array}{llccl}0.5 \mathrm{kHz} & 37.03(7.92) & 8.91(3.96) & 28.12 & <0.001 \\ 1 \mathrm{kHz} & 34.53(8.83) & 7.81(3.58) & 26.72 & <0.001 \\ 2 \mathrm{kHz} & 19.81(9.99) & 5.94(4.83) & 13.87 & <0.001 \\ 4 \mathrm{kHz} & 24.75(11.00) & 11.41(9.69) & 13.34 & <0.001\end{array}$




\section{Bone Conduction Threshold}

The difference in bone conduction at $0.5 \mathrm{kHz}, 1 \mathrm{kHz}$ and $2 \mathrm{kHz}$ before and after surgery was statistically significant $(P \leq 0.001)$. The difference between bone conduction at $4 \mathrm{kHz}$ before and after surgery was not statistically significant $(P=0.402)$.

\section{Air Conduction Threshold}

The differences in air conduction at all frequencies $(0.5 \mathrm{kHz}, 1 \mathrm{kHz}, 2 \mathrm{kHz}, 4 \mathrm{kHz})$ before and after surgery were highly statistically significant $(P \leq 0.001)$.

Air-Bone Gap (AB gap)

The differences in air-bone gaps at all frequencies $(0.5 \mathrm{kHz}, 1 \mathrm{kHz}, 2 \mathrm{kHz}$, $4 \mathrm{kHz}$ ) before and after surgery were highly statistically significant $(P \leq 0.001)$.

\section{Average}

The mean air conduction thresholds of all patients were evaluated in 500, 1000, 2000 and $4000 \mathrm{~Hz}$ frequencies. The average preoperative bone conduction threshold was $21.53 \mathrm{~dB}$ which was reduced to $16.21 \mathrm{~dB}$ postoperatively. The difference in bone conduction thresholds was statistically significant, $P=0.009$ (before $X=21.53$; after $X=16.21$ ). The difference in air conduction PTA at all four frequencies before and after surgery was highly statistically significant, $P \leq 0.001$ (before $X=51.13$; after $X=23.91$ ). The difference in air-bone gap PTA at all four frequencies before and after surgery was highly statistically significant,

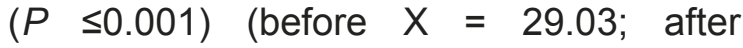
$X=8.51)($ Table 2$)$.

Table 2: The pure tone average of the bone conduction, air conduction and air-bone gap before and after surgery.

PTA Bone conduction Air conduction AB-gap

Before surgery

After surgery

$P$ value
$21.53 \mathrm{~dB}$

$16.21 \mathrm{~dB}$

$<0.001$
$51.13 \mathrm{~dB}$

$29.03 \mathrm{~dB}$

$23.91 \mathrm{~dB}$

$8.51 \mathrm{~dB}$ 
The outcome of stapedotomy in adult patients .......

https:/ / doi.org/ 10.15218/ zjms.2019.001

Figure 1 shows three case examples post surgery. of pure tone audiogram pre and

Case 1

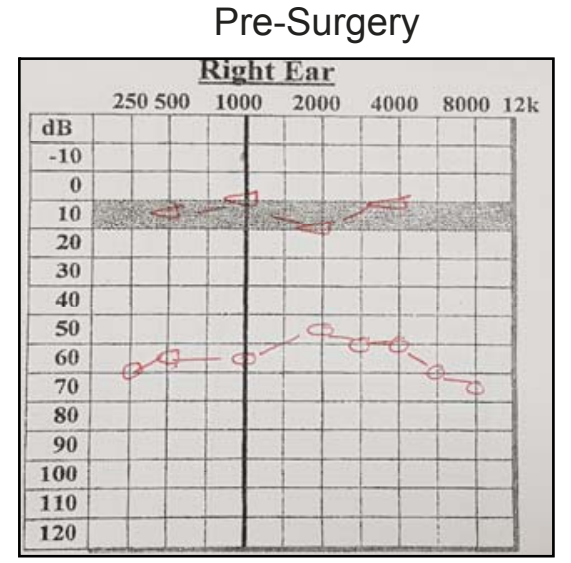

Case 2

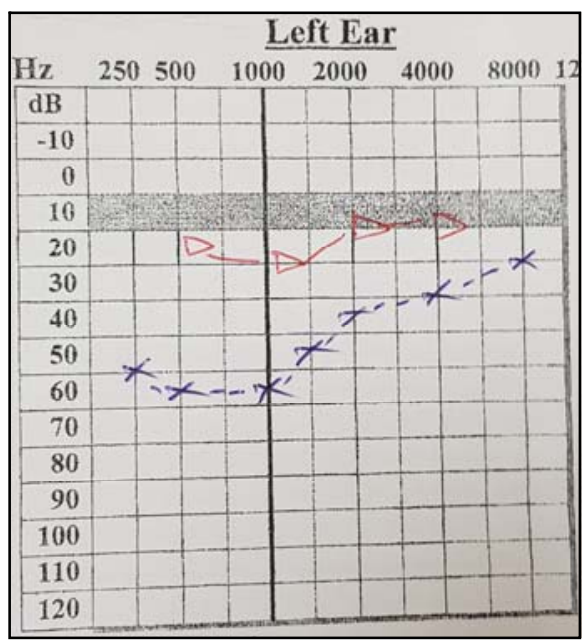

Case 3

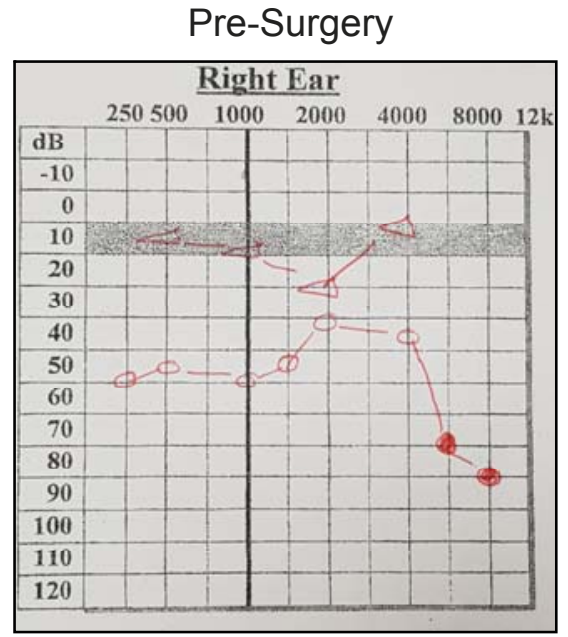

\section{Post- Surgery}

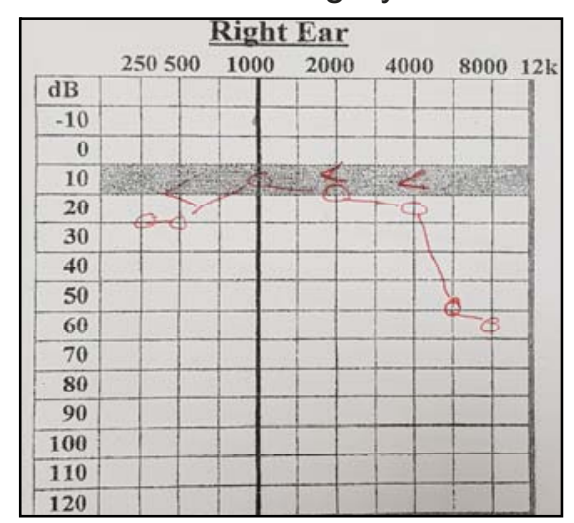

Post- Surgery

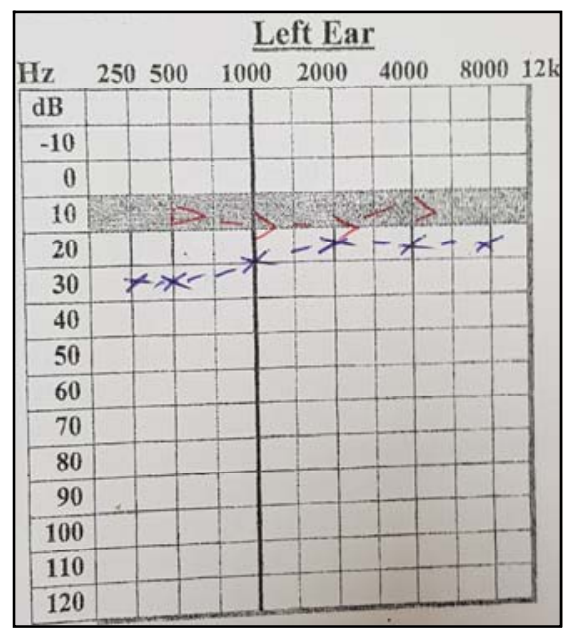

Post- Surgery

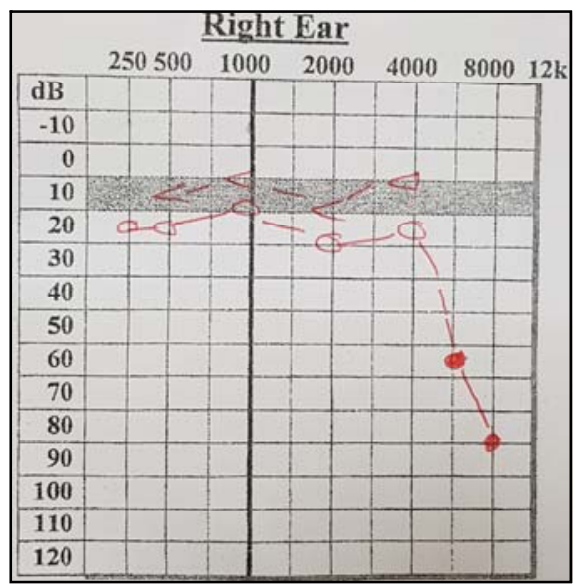

Figure 1: Case examples of Pure Tone Audiogram pre and post surgery. 


\section{Discussion}

Various surgical techniques have been used to treat otosclerosis, but stapedotomy still remains the method of choice. ${ }^{18}$ In our study, all patients were surgically treated by small fenestra stapedotomy of the stapes footplate. The main goal of surgical techniques has been to improve patients' hearing function and to eliminate the accompanying symptoms of the disease, such as tinnitus and dizziness. Most studies dealing with the outcomes of surgical treatment of otosclerosis depend on audiological testing before and after surgery, presuming that audiological measurements reflect the patient's subjective experience regarding the treatment outcome.

\section{Bone conduction}

In the current study the average preoperative bone conduction value at $500 \mathrm{~Hz}$ was at the level of $18.75 \mathrm{~dB}$ preoperatively and $15.31 \mathrm{~dB}$ postoperatively, this was considered statistically significant. In addition, the change of average bone conduction value before and after surgery was also achieved a statistical significance at $1000 \mathrm{~Hz}$ and $2000 \mathrm{~Hz}$. However, at $4000 \mathrm{~Hz}$ the mean values measured before and after surgery were $17.19 \mathrm{~dB}$ and $17.66 \mathrm{~dB}$, respectively and thus showing no statistically significant difference at $4000 \mathrm{~Hz}$. Thus in our study, there was a statistically significant difference in the mean of pre- and postoperative bone conduction values at frequencies 500,1000 and $2000 \mathrm{~Hz}$ but the difference was not statistically significant at $4000 \mathrm{~Hz}$. Similar to our data several studies have noted that in otosclerotic patients BC thresholds are better in the postoperative than in the preoperative period. However, the degree of BC improvement differs in various studies. Awengen et al. ${ }^{24}$ noticed an improvement in $\mathrm{BC}$ after stapedectomy in $500,1,000$ and $2,000 \mathrm{~Hz}$ but its deterioration in $4,000 \mathrm{~Hz}$. Arnoldner et al. $^{25}$ showed some BC improvement in conventional or laser-assisted surgery. Aarnisalo et $\mathrm{al}^{26}$ showed an improvement of $\mathrm{BC}$ about $4.5 \mathrm{~dB}$ in stapedectomy, and $3.1 \mathrm{~dB}$ is stapedotomy group. In a study by Moscillo et al. ${ }^{27}$ the BC improvement was 4 and $7.1 \mathrm{~dB}$ in two different types of surgery, but the difference was not statistically significant. He also showed that this improvement might occur in a different frequency. On the other hand, various studies have stated that the surgery does not affect the bone conduction value. In a study by Vincent et al. $^{23} \mathrm{BC}$ did not change after stapes surgery. Similarly, Quaranta et al. ${ }^{28}$ reported the changes of average bone conduction value at 1000 $\mathrm{Hz}, 2000 \mathrm{~Hz}$ and $4000 \mathrm{~Hz}$ at the level of $0.2 \mathrm{~dB}$. In 2005, Lazaro et al. reported a small change in the mean pre- and postoperative bone conduction values at $2000 \mathrm{~Hz}$ (32.73dB pre- and $30.78 \mathrm{~dB}$ post-operatively. ${ }^{29}$ It is important to know that BC threshold not only depends on the direct transmission of the vibration to the inner ear fluids through the skull, but it is also related to the relative movement of the footplate in the oval window due to the different inertia of the ossicular chain and the otic capsule. ${ }^{30,31}$ The mechanical process by which the energy of the sound waves entering the external canal and middle is utilized is known as Carhart phenomenon. ${ }^{32}$ In patients with otosclerosis, this energy is not utilized properly as there is a reduction of ossicular chain fluctuations caused by stapes fixation. This eventually will lead to difficulties in transmission of stimuli to the inner ear mostly at a frequency of $2000 \mathrm{~Hz} .{ }^{32}$ Thus, the major drop in bone conduction is observed at this frequency.

\section{Air conduction}

The average air conduction at $500 \mathrm{~Hz}$ before surgery was $55.78 \mathrm{~dB}$. After surgery, the average air conduction was $23.59 \mathrm{~dB}$. This result is highly statistically significant, indicating that otosclerosis surgery results in the improvement of conductive hearing loss. At $1000 \mathrm{~Hz}$, the average preoperative air conduction was $57.50 \mathrm{~dB}$, reaching $22.03 \mathrm{~dB}$ after surgery. This result is considered highly statistically 
significant, confirming the successful outcome of the procedure at the frequency of $1000 \mathrm{~Hz}$. The mean air conduction values at $2000 \mathrm{~Hz}$ were $47.97 \mathrm{~dB}$ and $21.72 \mathrm{~dB}$ before and after surgery, respectively. This improvement is considered highly statistically significant. The comparison of the mean pre- and postoperative air conduction values at $4000 \mathrm{~Hz}$ revealed a statistically significant difference. The mean values obtained before and after surgery were $43.28 \mathrm{~dB}$ and $28.28 \mathrm{~dB}$, respectively. According to the above results, the functional hearing tests and their comparison demonstrate the effectiveness and success of stapedotomy as a valuable method in treating otosclerosis. At all frequencies, the improvement in PTA value of air conduction before and after surgery was statistically significant. The data in the present study are very similar to the results reported by Lazaro et al. in their study done in $2005 .{ }^{29}$ Their data revealed the following: the average preoperative air conduction at 500 was $60.2 \mathrm{~dB}$ before surgery and $36.8 \mathrm{~dB}$ after surgery. Preoperative and postoperative values at $1000 \mathrm{~Hz}$ were $56.6 \mathrm{~dB} 34.5 \mathrm{~dB}$, respectively. The scores obtained at $2000 \mathrm{~Hz}$ were $52.7 \mathrm{~dB}$ before surgery and $36 \mathrm{~dB}$ after surgery, whereas mean preoperative and postoperative air conduction values at $4000 \mathrm{~Hz}$ were $54.3 \mathrm{~dB}$ and $45 \mathrm{~dB}$, respectively.

\section{Air-bone gap}

The purpose of otosclerosis surgery and the greatest benefit resulting from it are the improvement of air conductivity and closure of the air-bone gap. The mean air-bone gap at $500 \mathrm{~Hz}$ before the surgery was $37.03 \mathrm{~dB}$, whereas the value after surgery was $8.91 \mathrm{~dB}$. This difference was highly statistically significant. The average air-bone gap at $1000 \mathrm{~Hz}$ before surgery was $34.53 \mathrm{~dB}$ while the postoperative value was $7.81 \mathrm{~dB}$, which is considered highly statistically significant difference. At $2000 \mathrm{~Hz}$ the values were $19.81 \mathrm{~dB}$ before surgery and $5.94 \mathrm{~dB}$ after surgery, and the difference was highly statistically significant. The average air-bone gap at $4000 \mathrm{~Hz}$ before the operation was at the level of $24.75 \mathrm{~dB}$, whereas the value recorded after surgery was 11.41 $\mathrm{dB}$, resulting in a statistically significant difference. Overall our study demonstrated the following improvement of average air-bone gap values: at $500 \mathrm{~Hz}$ by 28.12 $\mathrm{dB}$, at $1000 \mathrm{~Hz}$ by $26.72 \mathrm{~dB}$, at $2000 \mathrm{~Hz}$ by $13.87 \mathrm{~dB}$, and at $4000 \mathrm{~Hz}$ by $13.34 \mathrm{~dB}$. Our data fully corresponds with the results obtained by Vincent et al. ${ }^{23}$ Their study demonstrated the following improvement of average air-bone gap values: at $500 \mathrm{~Hz}$ by $26.5 \mathrm{~dB}$, at $1000 \mathrm{~Hz}$ by $25.4 \mathrm{~dB}$, at 2000 $\mathrm{Hz}$ by $13.3 \mathrm{~dB}$, and at $4000 \mathrm{~Hz}$ by $8.2 \mathrm{~dB}$. Very close results were also reported by the research of Belgin and Yilmaz in 2004. ${ }^{33}$ The authors reported the improvement of the air-bone gap of 30.8 $\mathrm{dB}$ at $500 \mathrm{~Hz}$, whereas the scores at 1000 $\mathrm{Hz}$ and $2000 \mathrm{~Hz}$ were $25.5 \mathrm{~dB}$ and 14.3 $\mathrm{dB}$, respectively. However, at $4000 \mathrm{~Hz}$ the increase of only $2.9 \mathrm{~dB}$ was demonstrated and this was not considered statistically significant. Contrary to the aforementioned study, our results at $4000 \mathrm{~Hz}$ showed a statistical significance, as the improvement of the average air-bone gap was $13.34 \mathrm{~dB}$.

\section{Average (all frequencies)}

The improvement in the PTA value of air conduction before and after surgery was statistically significant. The mean air conduction PTA values before and after surgery were $51.13 \mathrm{~dB}$ and $23.91 \mathrm{~dB}$, respectively, thus a difference of $27.22 \mathrm{~dB}$ was demonstrated. Similarly, the mean PTA value of bone conduction before and after surgery was statistically significant. Bone conduction values before and after surgery were $21.53 \mathrm{~d} B$ and $16.21 \mathrm{~d} B$ respectively. The difference between the bone conduction PTAs before and after surgery was $5.32 \mathrm{~dB}$. The improvement of pre- and postoperative air-bone gap PTA values was also highly statistically significant. Prior to surgery, the PTA air-bone gap was $29.03 \mathrm{~dB}$, and after surgery, the value was $8.51 \mathrm{~dB}$. The difference between the air-bone gap PTAs 
before and after surgery was $20.52 \mathrm{~dB}$. The goals of otosclerosis surgery are the closure of the air-bone gap and producing the capability of hearing without amplification. Success, defined as closure of the air-bone gap to less than $10 \mathrm{~dB} .{ }^{18}$ In our study, the closure of the air-bone gap to less than $10 \mathrm{~dB}$ was obtained in all of our patients as the average air-bone gap after surgery was $8.51 \mathrm{~dB}$. In 2006, Vincent et al. ${ }^{23}$ performed a prospective study over a period of 14 years. The air-bone gap was $\leq 10 \mathrm{~dB}$ in $94.2 \%$ of cases. In 2013 , Oeken et al. ${ }^{34}$ published a study of 256 cases of stapedotomy in which the postoperative air-bone gap was $\leq 10 \mathrm{~dB}$ in $86 \%$. In 2013 , Ataide et al. ${ }^{35}$ observed the same result in $75.8 \%$ of patients undergoing stapedotomy. In his study of otosclerosis, Sargent et al. ${ }^{11}$ reported that in patients who had undergone otosclerosis surgery the closure of air-bone gap within a range up to $10 \mathrm{~dB}$ in $90 \%$ of patients. The research of Rauka and Halik ${ }^{36}$ in 2005, who compared the PTA- air-bone gap before and after surgery, a gap of $10 \mathrm{~dB}$ or less was observed in $85.19 \%$ of patients. Therefore, the audiometric results obtained in the present study are consistent with those in the literature. After all, it is argued that the relation between the average air-bone gap values before and after surgery cannot be considered a reliable indicator of the success of the surgical procedure, especially if there is a decrease in bone conduction during the postoperative period $^{8}$. In the aforementioned study, no significant decrease in bone conduction was observed after surgery. Thus the average values for air-bone conduction were considered statistically significant. Unlike the above study, our research showed a significant reduction of the bone conduction after surgery except at 4000 $\mathrm{Hz}$. Also as it is indicated in the earlier section, the reduction in bone conduction thresholds after surgery was also reported by Awengen ${ }^{24}$, Arnoldner et al., ${ }^{25}$ Aarnisalo et al. ${ }^{26}$ and Moscillo et al. ${ }^{27}$

\section{Conclusion}

This study concludes that the significant reduction in the air-bone gap, regardless of the change in bone conduction threshold, is a good indicator of the success of the stapedotomy surgery in patients with otosclerosis.

\section{Competing interests}

The authors declare that they have no competing interests.

\section{References}

1. Stefanović P. Otorinolaringologija maksilofacijalnom patologijom. Beograd: Naučna knjiga; 1994.

2. Makarem AO, Hoang TA, Lo WW, Linthicum FH, Fayad JN. Cavitating otosclerosis: clinical, radiologic and histopathologic correlations. Otol Neurotol 2010; 31(3):381-4.

3. Menger DJ, Tange RA. The aetiology of otosclerosis: a review of the literature. Clin Otolaryngol Allied Sci 2003; 28(2):112-20.

4. Quinn BF, Ryan WM. Otosclerosis: grand rounds presentation, UTMB, Dept. of Otolaryngology; 2003.

5. Young G. Otosclerosis: grand rounds presentation. UTMB; 1996.

6. Ueda H, Miyazawa T, Asahi K, Yanagita N. Factors affecting hearing results after stapes surgery. J Laryngol Otol 1999; 113(5):417 -21 .

7. Janošević LJ, Janošević S. Etiopatogeneza otoskleroze. Beograd: Naučna knjiga; 1986.

8. Souza JC, Bento RF, Pereira LV, Ikari L, Souza SR, Della Torre AA, et al. Evaluation of functional outcomes after stapes Surgery in patients with clinical otosclerosis in a teaching institution. Int Arch Otorhinolaryngol 2016; 20:39 $-42$.

9. Declau F, Van Spaendonck M, Timmermans JP, Michaels L, Liang J, Qu JP, Van de Heyning P. Prevalence of otosclerosis in an unselected series of temporal bones. Otol Neurotol 2001; 22(5):596-602.

10. Al- Husban H. Outcome of management of otosclerosis by stapedotomy compared to stapedectomy in a Jordanian population. Oman Med J 2013; 28(1):36-8.

11. Sargent E. Otosclerosis: A review for audiologists. 2001. (Accessed on January 21, 2017, at http://www.audiologyonlin.com/Articles/ article_detail.asp?article_id=288).

12. Lolov $\mathrm{S}$. Otosclerosis is a conformational disease. Med Hypotheses 2004; 62(1):121-3.

13. House HP, De la Cruz A, Friedman RA, Linthicum HF. Otosclerosis overview. Hearing Health 2003; 19:1. 
14. McGuirt WT, Fukushima K, Willems PJ, Van Camp G, Smith RJ. Linkage of a gene for otosclerosis to chromosome 15q25-q26 and identification of a candidate gene. Aggrecan. ARO abstracts; 1998:428.

15. Markou K, Goudakos J. An overview of the etiology of otosclerosis. Eur Arch Otorhinolaryngol 2009; 266:25-35.

16. Glasscock ME III, Storper IS, Haynes DS, Bohrer PS. Twenty-five years of experience with stapedectomy. Laryngoscope 1995; 105; (9 Pt 1):899-904.

17. Rondini-Gilli E, Bozorg GA, Boutin P, Tormin Borges Crosara PF, Mosnier I, Bouccara D, et al. Otosclerosis surgical techniques and results in 150 patients. Ann Otolaryngol Chir Cervicofac 2002; 119(4):227-33.

18. Dankuc D, Pejaković N, Komazec Z, Vlaški L. Functional hearing results in patients with otosclerosis before and after stapedotomy. Med Pregl 2012; LXV(1-2):54-8.

19. Antoli-Candela F, McGill T, Peron D. Histopathological observations on the cochlear changes in otosclerosis. Ann Otol Rhinol Laryngol 1977; 86(6 Pt 1):813-20.

20. Chole RA, McKenna M. Pathophysiology of Otosclerosis. Otology \& Neurotology 2001; 22(2):249-57.

21. Gjurić M, Rukavina L. Evolution of stapedectomy prostheses over time. See comment in Pub Med Commons below Adv Otorhinolaryngol 2007; 65:174-8.

22. Kisilevsky VE, Dutt SN, Bailie NA, Halik JJ. Hearing results of 1145 stapedotomies evaluated with Amsterdam hearing evaluation plots. J Laryngol Otol 2009; 123(7):730-6.

23. Vincent $R$, Sperling NM, Oates J, Jindal $M$. Surgical findings and long-term hearing results in 3,050 stapedotomies for primary otosclerosis: a prospective study with the otology-neurotology database. Otol Neurotol 2006; 27(8)(suppl 2):S25 -47 .

24. Awengen DF. Change of bone conduction thresholds by total footplate stapedectomy in relation to age. Am J Otolaryngol 1993; 14:10510.

25. Arnoldner C, Schwab B, Lenarz T. Clinical results after stapedotomy: a comparison between the erbium: yttrium-aluminum- garnet laser and the conventional technique. Otol Neurotol 2006; 27:458-65.

26. Aarnisalo AA, Vasama JP, Hopsu E, Ramsay H. Long-term hearing results after stapes surgery: a 20-year follow-up. Otol Neurotol 2003; 24:56771.

27. Moscillo L, Imperiali $M$, Carra $P$, Catapano $F$, Motta G. Bone conduction variation poststapedotomy. Am J Otolaryngol 2006; 27:330 -3 .

28. Quaranta N, Besozzi G, Fallacara AR, Quaranta A. Air and conduction change after stapedotomy and partial stapedectomy for otosclerosis. Otolaryngol Head Neck Surg 2005; 133:116-20.

29. Pérez-Lázaro JJ, Urquiza R, Cabrera A, Guerrero C, Navarro E. Effectiveness assessment of otosclerosis surgery. Acta Otolaryngol (Stockh) 2005; 125(9):935-45.

30. Schick F. Alterations of bone conducted hearing in cases of modified middle ear mechanics. Eur Arch Otorhinolaryngol 1992; 249:268-72.

31. Tonndorf J. Bone conduction hearing. In: Keidel WD, NeV WD (eds) Handbook of sensory physiology. Berlin: Springer; 1994. P. 172-247.

32. House JW, Cunningham CDIII. Otosclerosis. In: Cummings CW (ed) Otolaryngology head and neck surgery, $4^{\text {th }}$ ed. Mosby, Philadelphia; 2005.

33. Yilmaz ST, Belgin E. Otosclerosis disease and importance of long term follow-up after stapedectomy. Otoscope 2004; 4:155-60.

34. Oeken J. Results of stapedotomies performed under general anesthesia. HNO 2013; 61(6):504-9.

35. Ataide AL, Bichinho GL, Patruni TM. Audiometric evaluation after stapedotomy with Fisch titanium prosthesis. Braz J Otorhinolaryngol 2013; 79(3):325-35.

36. Raut V, Halik J. Argon laser assisted small fenestra stapedotomy for otosclerosis. Auris Nasus Larynx 2005; 32:11-5. 